\title{
CNS Relapse in Acute Promyelocytic Leukemia: A Rare Occurrence
}

\author{
Umbreen Hashim, Ayesha Junaid, Imran N. Ahmad and Shawna Kamran
}

Hematology Department, Shifa International Hospital, Islamabad, Pakistan.

\begin{abstract}
Acute Promyelocytic leukemia with central nervous system involvement is one of the rarest occurrences. A 25 year old lady, admitted at Shifa International Hospital Islamabad, with complaints of menorrhagia, bruises, petechiae, headache and vomiting. Her laboratory investigation showed patient being in disseminated intravascular coagulation. Complete blood counts and Bone marrow examination showed significant promyelocytes and blasts with flow cytometric analysis consistent with acute promyelocytic leukemia (APL). PCR for PML-RAR $\alpha$ detected, CSF examination and its cytology revealed promyelocytes. CT scan of brain showed slight leptomeningeal enhancement. CNS involvement was diagnosed based on the appearance of APL blasts in cerebrospinal fluid (CSF). After treated with all-trans retinoic acid (ATRA), idarubicin, cytarabine and intrathecal methotrexate, she achieved morphological, molecular, and CNS remission. Patient was readmitted, 02 years later with complaints of headache, vomiting, right sided weakness and difficulty in speaking with suspicion of relapse. Lumber puncture was performed which showed many promyelocytes with Auer rods and diagnosis of CNS relapse of APL was made.
\end{abstract}

Keywords: Acute promyelocytic leukemia, central nervous system involvement, relapse of CNS. doi.org/10.21089/njhs.11.0037

\section{INTRODUCTION}

Central nervous system (CNS) involvement in a case of acute promyelocytic leukemia at the time of initial diagnosis is an uncommon finding and relapse after its remission is even a more rare condition. CNS is the most common site of extramedullary relapse in (Acute Promyelocytic Leukemia) APL. Few cases of APL with CNS involvement at its initial time of the diagnosis were reported, [1] with incidence of CNS relapse in APL ranges from $0.6 \%$ to $2 \%$, associated with age, high leukocyte count and micro granular variant [2].

\section{CASE REPORT}

We report a case of 25 year old lady, with complaints of excessive per vaginal bleed, bruises, petechiae all over her body, head ache and vomiting. Her initial laboratory investigations showed leukocyte count $61 \times 10 \% / \mathrm{uL}$ with $66 \%$ Promyelocytes, $34 \%$ blasts, Hemoglobin level of $8.2 \mathrm{~g} / \mathrm{dL}$, and a Platelet count of $10 \times 10^{9} / \mathrm{uL}$. Her coagulation profile demonstrated severe disseminated intravascular coagulation (DIC), with a prothrombin time of $11 \mathrm{sec}$, a partial thromboplastin time of $76 \mathrm{sec}$, and a fibrinogen of 120 $\mathrm{mg} / \mathrm{dL}$. Her bone marrow biopsy revealed significant increase in promyelocytes $(78 \%)$ and myeloblasts $(22 \%)$.

Immunophenotyping of the bone marrow revealed that leukemic cells were positive for CD13, CD33, CD117,

*Address correspondence to this author at the Hematology Department, Shifa International Hospital, Islamabad, Pakistan.

E-mail: umbreenhashim@yahoo.com
CD34 (weak in minor subset), HLA DR (micro subset) and CD2 (minor subset). PCR for PML-RAR $\alpha$ fusion transcript in the BM specimen showed $(15 ; 17)$. CT scan of brain showed slight leptomeningeal enhancement. CSF examination with cytology showed many Promyelocytes, revealing CNS involvement at time of initial diagnosis [4, 5] Table $\mathbf{1}$.

Morphological and molecular remission was achieved with induction chemotherapy, followed by consolidation chemotherapy with all-trans retinoic acid (ATRA), idarubicin, cytarabine and was receiving intrathecal Methotrexate, Cytarabine and Hydrocortisone till CSF analysis was normal. Her post consolidation consecutive complete blood counts with bone marrow examination, and CSF examination showed no abnormal cells, negative PCR for PML-RAR $\alpha$ and cytogenetic report is still showing normal female karyotype with no numerical or structural abnormality and planned for maintenance therapy of APL (PETHEMA 2005 protocol) with addition of three monthly intrathecal therapy, but patient was classified as high risk according to Sanz criteria, due to high leukocyte count and low platelet counts [6-8].

After duration of 02 years she presented with severe head ache, confusion status, right sided weakness and difficulty in speaking, Suspicion of relapse in CNS was raised and Lumbar puncture was performed. Her cerebrospinal fluid examination, its cytology showed many abnormal promyelocytes with Auer rods, hence diagnosis of CNS relapse of APL was made. No molecular study was performed on CSF, as cytological examination was sufficient 
Table 1: Reported cases of APL with CNS involvement at the time of initial diagnosis [3].

\begin{tabular}{|c|c|c|c|c|c|c|c|c|c|c|c|}
\hline No. & Year & Age/Sex & $\begin{array}{c}\text { Initial WBC } \\
\left(\times 10^{9} / L\right)\end{array}$ & $\begin{array}{c}\text { Initial PLT } \\
\left(\times 10^{9} / L\right)\end{array}$ & $\begin{array}{l}\text { PML-RAR } \alpha \\
\text { (BM) }\end{array}$ & $\begin{array}{l}\text { PML-RAR } \alpha \\
\text { (CSF) }\end{array}$ & $\begin{array}{l}\text { Neurological } \\
\text { symptoms }\end{array}$ & ATRA & $\begin{array}{c}\text { CNS } \\
\text { treatment }\end{array}$ & Outcome & $\begin{array}{l}\text { Reference } \\
\text { No. }\end{array}$ \\
\hline 1 & 1987 & $43 / F$ & 0.9 & 17 & ND & ND & Headache & - & IT cytarabine, TBI & CR for $29 \mathrm{mo}$ & 5 \\
\hline 2 & 1988 & $45 / F$ & 1.6 & 3 & ND & ND & $\begin{array}{l}\text { Headache } \\
\text { photopobia }\end{array}$ & - & TBI & $\begin{array}{l}\text { Relapsed } \\
\text { after } 45 \text { mo }\end{array}$ & 6 \\
\hline $3^{*}$ & 2000 & $55 / \mathrm{M}$ & 29.3 & 49 & + & ND & Dysarthria, hemiplegia & + & ITT,TBI & CR & 7 \\
\hline 4 & 2003 & $3 / \mathrm{M}$ & 56.8 & 14 & + & ND & None & + & None & $\begin{array}{c}\text { Relapsed } \\
\text { after } 13 \mathrm{mo}\end{array}$ & 8 \\
\hline 5 & 2010 & $16 / \mathrm{F}$ & 6.4 & 15 & + & + & $\begin{array}{l}\text { Unsteady gait, } \\
\text { headache }\end{array}$ & + & IT cytarabine, TBI & CR & 9 \\
\hline 6 & 2010 & $43 / \mathrm{F}$ & 48.6 & 14 & + & ND & Altered mentality & + & IT MTX & Died 3 days later & Present case \\
\hline 7 & 2010 & $3 / F$ & 3.8 & 27 & + & ND & None & + & IT cytaratine & CR for $31 \mathrm{mo}$ & Present case \\
\hline
\end{tabular}
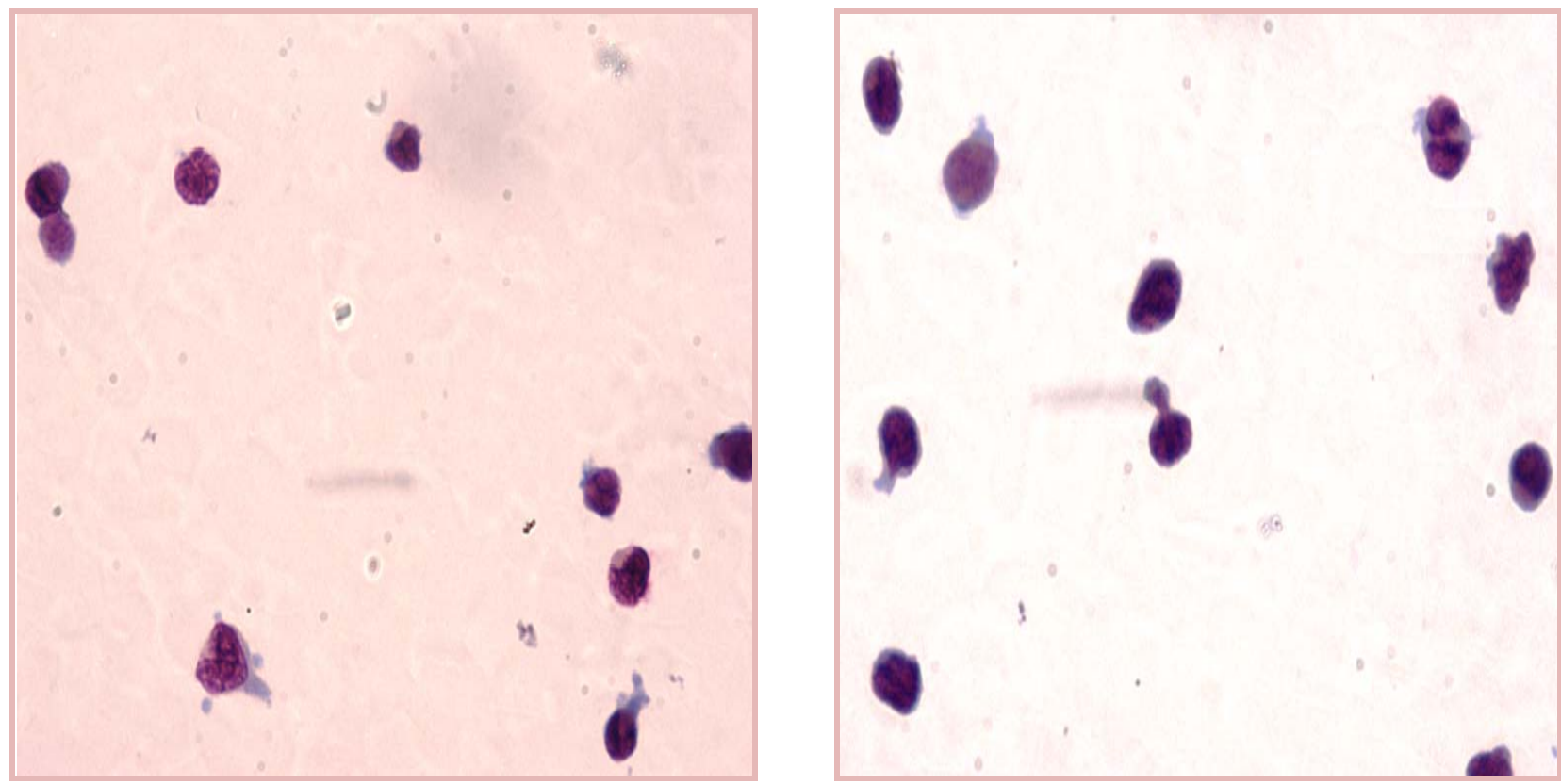

Fig. (1). Abnormal promyelocytes in CSF at initial time of diagnosis:

for diagnosis and was managed with induction treatment of CNS relapse, consist of weekly triple intrathecal therapy (ITT) with methotrexate, hydrocortisone, and cytarabine until complete clearance of blasts in the CSF, followed by 6 to 10 more spaced out ITT treatments as consolidation [10, $11]$.

\section{DISCUSSION}

Acute Promyelocytic Leukemia with $t(15 ; 17)$ is a type of AML in which abnormal Promyelocytes are significantly predominant in bone marrow and peripheral blood. It may be of hyper granular or hypo granular type [4] Fig. (1).
Acute Promyelocytic Leukemia is a distinctive entity associated with coagulopathy, different morphology and chromosomal abnormality. DIC is one of major cause of death in APL [6].

CNS involvement is a rare complication of APL. Despite of its improved therapy management, patients with high leukocyte count may relapse. The present study established that ATRA + arsenic compound-based combination therapy was effective in re-inducing morphological remission in relapsed patients with APL with previous exposure to ATRA + arsenic compounds; however, these patients remained question to low molecular remission rates and at high risk of 

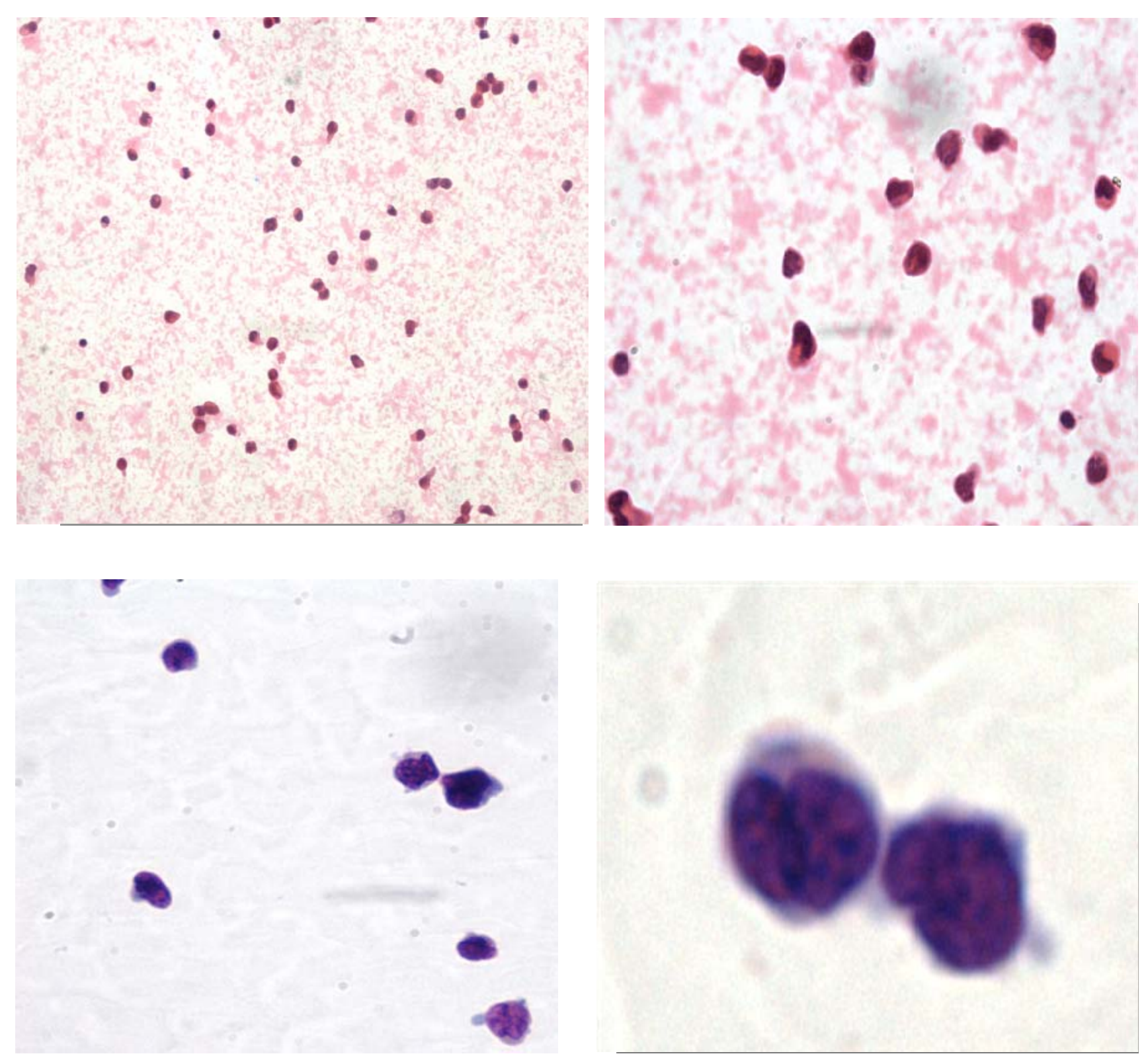

Fig. (2). Cytospun and CSF R/E slides after remission achievement showing myeloid precursors and many Promyelocytes with Auer rods.

secondary relapse. Chemotherapy regimens with high CNS penetrance (e.g., high-dose cytarabine) have been used in this situation and in patients responding to treatment, allogeneic or autologous transplant should be the consolidation treatment of choice including appropriate craniospinal irradiation $[9,10,11]$. Due to its low incidence and risk of bleed, diagnostic lumbar puncture is not routinely performed [5]. However, symptoms like Head ache, nausea, vomiting, vertigo and mental disturbance are clue to go for lumbar puncture. [12]. In summary, we report this case of CNS relapse in a case of APL after complete hematological remission. Any symptoms like head ache, nausea, vomiting in patients of APL should be thoroughly investigated. No molecular studies required as cytology of CSF is sufficient for the diagnosis [3].

\section{CONCLUSION}

Acute Promyelocytic Leukemia with CNS involvement is a rare occurrence [7] and relapse is even rarer and ranges from $0.6-2 \%$ of all cases. Our study shows CNS relapse in patient with APL after treatment with all trans retinoic acid and anthracylin.

\section{ACKNOWLEDGEMENT}

All authors made substantial contribution to conception, design, preparation, review and editing of the manuscript. 


\section{CONFLICT OF INTEREST}

Declared none.

\section{REFERENCES}

[1] Bhuller K, Kwan M. Acute promyelocytic leukaemia presenting with subarachnoid haemorrhage and complicated by central nervous system involvement. Blood Cancer J., 2011; 1: e25.

[2] Montesinos P, J Díaz-Mediavilla J, Debén G, Prates V, Tormo M, Rubio $\mathrm{V}$, et al. Central nervous system involvement at first relapse in patients with acute promyelocytic leukemia treated with all-trans retinoic acid and anthracycline monochemotherapy without intrathecal pro-phylaxis. Haematologia., 2009; 94: 1242-9.

[3] Ji M, Chi HS, Jang S, Park CJ, Lee JH, Seo JJ. Acute Promyelocytic Leukemia Presenting with Central Nervous System Involvement: A Report of 2 Cases. Korean J. Lab. Med., 2011; 31: 9-12.

[4] WHO Classification of Tumours of Haematopoietic and Lymphoid Tissues, Fourth Edition, Swerdlow, S.H., Campo, E., Harris, N.L., Jaffe, E.S., Pileri, S.A., Stein, H., Thiele, J., Vardiman, J.W.

[5] Collins C, Knoderer H. Central nervous system involvement at the time of presentation in acute promyelocytic leukemia. Pediatr. Blood Cancer, 2010; 54: 603-5.

[6] Bae SH, Ryoo HM, Cho HS, Lee JL, Lee KH, Hyun MS. Meningeal relapse in a patient with acute promyelocytic leukemia: a case report and review of the literature. J. Korean Med. Sci., 2004; 19: 311-4.

[7] Sakurai T, Kuroda H, Yamada M, Srihara Y, Jyomen W, Horako T, et al. Acute promyelocytic leukemia presenting with central nervous system involvement at initial diagnosis. Rinsho Ketsueki. 2013; 54: 574-8.

[8] Nadeem M, Mehmood S, Khan N, Mehmood F.Acute promyelocytic leukemia with early CNS relapse. JRMC. 2014; 18 : 308-9.

[9] Housman E, Chang P, Lane SW, Blinder R, Galinsky I, Kasari S, et al. CNS relapse in acute promyeloctyic leukemia. JCO. 2010; 28: e409-11.

[10] Sanz MA, Grimwade D, Tallman MS, Lowinberg B, Fenaur P, Estey EH, et al. Management of acute promyelocytic leukemia: recommendations from an expert panel on behalf of the European Leukemia Net. Blood. 2009; 113: 1875-91.

[11] Lu J, Huang X, Bao L, Jiang H, Zhu H, Jiang B. Treatment outcomes in relapsed acute promyelocytic leukemia patients initially treated with all-trans retinoic acid and arsenic compoundbased combined therapies. Oncoll Lett., 2014; 7: 177-82.

[12] Holbrook EK and Steven C. 1489 CNS Relapse in Acute Promyelocytic Leukemia: Incidence, Management and Outcome Clinically Abstract 54 ${ }^{\text {th }}$ ASH, 2012.

Copyright (C) 2016 NJHS - All Rights Reserved

This is an open-access article. 